\section{C64-to-PC: Transmitting data from a Commodore C64 to IBM-compatible PCs}

\author{
WOLFGANG PIEPER and HARALD LACHNIT \\ University of Giessen \\ Giessen, Federal Republic of Germany
}

The program C64-to-PC presented here makes it possible to transmit data collected with a Commodore C64 to an IBM-compatible PC. C64-to-PC is accompanied by a cable for connecting the user port of the $\mathrm{C} 64$ with the serial port (Coml) of an IBM-compatible PC.

The $\mathrm{C} 64$ computer is a very inexpensive and highly effective tool for conducting experimental research, because of its easy-to-handle interfacing capabilities and timers. However, compared to IBM-compatible PCs, it is very slow and ineffective for analyzing data. C64-toPC makes it possible to combine the advantages of both machines by enabling the user to transmit sequential files from the user port of the C64 to the serial port of any

Correspondence may be addressed to Wolfgang Pieper, Department of Psychology, Otto-Behaghel-Strasse 10, D-6300 Giessen, West Germany.
IBM-compatible PC. The necessary cable and electronics accompany the program.

There are two programs, one for the $\mathrm{C} 64$ and one for the PC. The name C64-to-PC refers to both. A C64 with floppy disk is needed to run the program on the Commodore computer. This program is written in Commodore 64 Basic. It enables the user to send any sequential file from the floppy disk to the user port of the C64.

Any IBM-compatible PC with at least one serial port meets the requirements for running the second program. This program is written in Clipper (summer '87) and needs about $200 \mathrm{~K}$. The program runs under PC-DOS, version 3.1 or higher. It enables the user to receive data on the serial port of the PC and to store these data as a regular DOS file (ASCII).

The two diskettes (C64, 5.25"; PC, 3.5" or 5.25") containing the programs and a user's guide, plus the connecting cable, are available for $\$ 35$ (including mailing). Programs may be obtained from Wolfgang Pieper or Harald Lachnit, Department of Psychology, University of Giessen, Otto-Behaghel-Strasse 10, D-6300 Giessen, West Germany. Bitnet: LACHNIT@DGIHRZ01.

(Manuscript received October 30, 1989; accepted for publication November 4,1989 .) 